\title{
PERSPECTIVE \\ Differential sensitivity to the environment: contribution of cognitive biases and genes to psychological wellbeing
}

\author{
E Fox $^{1,3}$ and CG Beevers ${ }^{2,3}$
}

Negative cognitive biases and genetic variation have been associated with risk of psychopathology in largely independent lines of research. Here, we discuss ways in which these dynamic fields of research might be fruitfully combined. We propose that gene by environment $(G \times E)$ interactions may be mediated by selective cognitive biases and that certain forms of genetic 'reactivity' or 'sensitivity' may represent heightened sensitivity to the learning environment in a 'for better and for worse' manner. To progress knowledge in this field, we recommend including assessments of cognitive processing biases; examining $\mathrm{G} \times \mathrm{E}$ interactions in 'both' negative and positive environments; experimentally manipulating the environment when possible; and moving beyond single-gene effects to assess polygenic sensitivity scores. We formulate a new methodological framework encapsulating cognitive and genetic factors in the development of both psychopathology and optimal wellbeing that holds long-term promise for the development of new personalized therapies.

Molecular Psychiatry (2016) 21, 1657-1662; doi:10.1038/mp.2016.114; published online 19 July 2016

\section{INTRODUCTION}

Genetic and environmental influences make substantive contributions to psychological wellbeing and evidence suggests that certain genetic variants, previously associated with vulnerability, may also facilitate adaptive functioning in positive or supportive environments (that is, differential susceptibility). ${ }^{1-3}$ The essence of the differential susceptibility hypothesis (DSH) is that with similar group sizes of more and less susceptible individuals there will be no main genetic effect. Instead, there will be a crossover interaction with susceptible individuals doing worse in adverse environments but better in supportive environments than less susceptible individuals. This pattern does of course undermine large-scale genome-wide association studies (GWAS) that look only for main genetic effects.

Little is known about the psychological or biological mechanisms that underlie differential susceptibility. A recent review ${ }^{4}$ outlines how neurobiological reactivity might underlie individual variation in sensitivity to the environment in a sophisticated multilevel approach, and several other potential mechanisms have been highlighted. ${ }^{1-4}$ However, a hitherto neglected variable in this literature is the potential role of systematic biases in cognitive processing that are likely to influence individual variation in sensitivity to the environment. In this Perspective, we suggest that biased cognitive processing of emotional information may be one critical pathway through which differential susceptibility influences psychological wellbeing. Progress in investigating gene by environment $(\mathrm{G} \times \mathrm{E})$ interactions has been held back by several factors: the search for only genetic main effects; the use of relatively small sample sizes; focus on single-genetic variants; use of correlational designs, and failure to examine the possibility that genetic influence may turn from a 'problem' to an 'advantage', depending on the nature of the environment. Moreover, most $\mathrm{G} \times$ E studies do not directly assess selective processing biases and these-generally unmeasured-cognitive factors may be one important consequence of $\mathrm{G} \times \mathrm{E}$ interactions.

There is potentially much to be gained by integrating work on cognitive biases for emotional information with work on molecular genetics and environmental context. In this sense, the current comments are prospective, in that many of the points we raise relate to the promise of future work rather than to work that has been completed. We formulate a theoretical framework to help orient research in this rapidly developing field.

\section{SEARCH STRATEGY AND SELECTIVE CRITERIA}

Web of Science and Google Scholar was searched on 20 April 2016 for 'Bias AND SNP OR Genetic' and Google Scholar was searched on 19 May 2016 for 'differential susceptibility'. Papers of relevance to our hypothesis were selected.

\section{COGNITIVE PROCESSING AND DIFFERENTIAL SENSITIVITY TO THE ENVIRONMENT}

Fundamental cognitive operations such as negative attentional bias (AB)-the tendency to preferentially orient attention toward threat-whereas important for survival-can markedly influence sensitivity to the environment. For instance, preferential attentional processing of threat-related images is a strong predictor of cortisol reactivity to stressful environments up to 8 months later, ${ }^{5}$ predicts increases in posttraumatic stress disorder among people with high combat exposure ${ }^{6}$ and is often exacerbated in anxiety disorders. $^{7-9}$ Thus, variability in response to the same environmental risk is closely associated with individual differences in cognitive processing biases.

The causal influence of $A B$ on affective reactivity to stressful experiences has been investigated by directly manipulating $A B s$ for threat. In a seminal study, experimental induction of a negative

\footnotetext{
${ }^{1}$ Department of Experimental Psychology, University of Oxford, Oxford, UK and ${ }^{2}$ Department of Psychology and Institute for Mental Health Research, University of Texas at Austin, Austin, TX, USA. Correspondence: Professor E Fox, Department of Experimental Psychology, University of Oxford, Tinbergen Building, 9 South Parks Road, Oxford OX1 3UD, UK. E-mail: Elaine.fox@psy.ox.ac.uk

${ }^{3}$ These two authors contributed equally to this work.

Received 15 March 2016; revised 19 May 2016; accepted 1 June 2016; published online 19 July 2016
} 
$A B$ by means of a computer-implemented 'attentional bias modification' (ABM) procedure resulted in enhanced stress reactivity among healthy individuals. ${ }^{10}$ Conversely, experimentally decreasing negative $A B$ can reduce stress reactivity. Thus, training attention toward positive stimuli in people with social phobia, who typically have an $A B$ for threat stimuli, produced greater reductions in self-reported, behavioral and physiological measures of anxiety during a subsequent social stressor relative to control conditions. ${ }^{11}$ Other works show that when negative attention biases are successfully modified in clinically anxious populations, reductions in measures of anxiety typically occur. ${ }^{12,13}$

A recent meta-analysis concluded that $A B M$ research is hampered by small low-quality trials, risk of publication bias and small effect sizes. ${ }^{14}$ Crucially, however, this meta-analysis focused on clinical outcome and did not consider whether or not a shift in attention bias had actually occurred. This is critical because when $A B$ does not shift in the predicted direction cognitive models predict that 'no' change in symptoms should follow.

Research indicates that when attention bias does change significantly in the appropriate direction, a reliable impact on stress sensitivity and clinically relevant outcome measures typically follows. ${ }^{15}$ There is, however, a shortage of high-quality trials of $A B M$ and the effectiveness of $A B M$ manipulations in producing sustained changes in bias is not yet optimal. Although this experimental technique offers great potential, further basic science research is clearly required. ${ }^{16}$

Evidence also suggests that modifying other clinically relevant cognitive biases-such as biases in how ambiguous situations are interpreted-can reduce clinical symptoms of affective disorders. ${ }^{13}$ Importantly, research on modifying cognitive biases moves us beyond correlational research and toward identifying the causal mechanisms that confer sensitivity to the environment.

\section{GENETIC VARIATION INFLUENCES DIFFERENTIAL SENSITIVITY TO THE ENVIRONMENT}

In largely unrelated research, many studies have examined whether genetic variation is associated with enhanced sensitivity to the environment. ${ }^{17}$ Utilizing twin study designs, genetic variation has been shown to interact with environmental adversity to predict the onset of psychopathology, such as depression and anxiety. ${ }^{18}$ Although controversial, several studies have linked candidate polymorphisms with increased sensitivity to the environment. A well-researched genetic variant is the serotonin transporter-linked polymorphic region (5-HTTLPR), a repeat length polymorphism in the promoter region of the human serotonin transporter gene (SLC6A4 or 5-HTT). Following an initial pioneering study ${ }^{19}$ numerous studies have reported that 5-HTTLPR short (S) allele homozygotes are more sensitive to the environment in both human ${ }^{20,21}$ and non-human samples. ${ }^{22}$ Although there have been several failures to replicate, ${ }^{23}$ the most recent meta-analysis ${ }^{24}$ indicates that those with the less-efficient S-allele are at greater risk of psychopathology when exposed to childhood adversity, although the possibility of type I error does need to be considered. $^{25}$

Regardless of whether any specific candidate gene increases sensitivity to the environment, there is general agreement that, like cognitive biases, genetic variation influences sensitivity to the environment, which in turn, increases vulnerability to psychopathology. However, as suggested by the DSH, certain genetic profiles may not operate exclusively as 'vulnerability' genes, but rather as 'plasticity' or 'malleability' genes that influence functioning in a 'for better and for worse' manner. ${ }^{1,2,3,4,26,27}$ The DSH overlaps with the diathesis-stress model but assumes that those with a more 'malleable' genetic profile are highly sensitive to the affective environment so that negative environments will have a deleterious effect, whereas positive and supportive environments will enhance psychological functioning. ${ }^{1,26}$ Most studies, however, have focused on anxiety and depression, and have examined the 5-HTTLPR as the genetic factor, so we focus on this polymorphism in this review; however, as we discuss at the end of this article, future work needs to assess genetic variation and a wider range of environments much more broadly.

An early study $^{28}$ reported that children exposed to early environmental risk demonstrated higher depressive symptoms if they carried two copies of the 5-HTTLPR S-allele versus two copies of the L-allele as predicted by diathesis stress, but also exhibited the 'least' depressive symptoms if exposed to supportive environments, as opposed to just the absence of adversity. This is consistent with findings that in non-risk environments adolescent females with two copies of the S-allele show reduced risk of depression relative to those with two copies of the L-allele. ${ }^{29}$ Using positive affect as an outcome, children with two copies of the 5-HTTLPR S-allele were found to be highly responsive to both supportive and unsupportive parenting. ${ }^{30}$ Across three independent studies, evidence for the DSH was found using parental report, child reports and direct observation of child-parent interactions. In all cases, poor parenting was associated with lower positive affect, whereas in the first two studies good parenting was also associated with higher positive affect with the same trend occurring for direct observation as the outcome measure.

Further evidence comes from studies reporting that number of lifetime negative events was associated with higher self-reported neuroticism, whereas positive events were closely tied to lower neuroticism and higher life satisfaction among S homozygotes, but not among L homozygotes. ${ }^{31,32}$ Similarly, marital satisfaction over a 13-year period was predicted by emotional behaviors (both positive and negative) exhibited during an initial couples interaction among $S$ homozygotes, but not for other 5-HTTLPR genotypes, again revealing a 'for better and for worse' pattern. ${ }^{33}$ A cumulative genetic approach that assessed the impact of variation on the 5-HTTLPR as well as variation on a 17-bp variable-number tandem repeat (VNTR) in the second intron region of the $5-\mathrm{HTT}$ gene (known as STin2 VNTR) demonstrated that women with more socalled 'risk' alleles (S-allele and 12-repeat allele) had higher rates of maternal post partum depression in adverse environments, but reduced rates in favorable environments supporting the DSH. ${ }^{34}$ The strongest evidence comes from meta-analyses that show support for the DSH across a range of genetic variants. 3,35

A recent study extended testing the DSH from a candidate gene approach to a GWAS approach. ${ }^{36}$ A polygenic score of environmental sensitivity was derived in a sample of monozygotic twins by a novel method of assessing within-pair emotional problems as a function of genotype. This polygenic sensitivity score (PSS) was then found to moderate the effects of parenting on emotional problems and response to psychological therapy in separate samples of children. Although replication is required, this GWAS indicates that those with the strongest environmental sensitivity may be most likely to develop emotional problems in difficult environments, but also benefit most from highly supportive environments such as intensive psychological interventions.

\section{COGNITIVE BIAS AS A PUTATIVE MECHANISM UNDERLYING DIFFERENTIAL SUSCEPTIBILITY}

Cognitive and genetic markers of susceptibility to psychopathology have typically been investigated in separate lines of research. An emerging literature, however, suggests that cognitive and genetic factors are not independent of each other and in fact may operate in concert to increase sensitivity to adverse (and perhaps positive) environments. Thus, meta-analysis shows that $\mathrm{S}$ homozygotes on the 5-HTTLPR typically exhibit larger 'negative' $A B$ than their LL counterparts. ${ }^{37}$ To illustrate our point, we highlight findings from several studies, but note that this Perspective Review does not aim to provide an exhaustive review of the 
genetics and cognitive bias literature. For more thorough reviews, the reader is advised to referto other articles. ${ }^{37,38}$

A recent study capitalized on naturally occurring variability in young peoples' emotional reactivity to the challenges of a first semester at university to investigate how cognitive biases and genetic variation might interactively contribute to affective reactivity. ${ }^{39}$ Although negative $A B$ predicted increases in anxiety across the semester regardless of the genotype, greater preferential processing of negative information at the start of the academic year predicted elevations in dysphoria only for those with two copies of the less-efficient S-allele. ${ }^{39}$

Another study assessed cognitive re-appraisal-an adaptive form of emotion regulation that is often impaired in anxiety disorders-in addition to variation on the 5-HTTLPR. ${ }^{40}$ Those with two copies of the S-allele had increased social anxiety symptoms and reduced use of re-appraisal in comparison with those with two copies of the L-allele. Critically, the degree of cognitive re-appraisal acted as a mediator of the association between the 5 -HTTLPR polymorphism and social anxiety symptoms. ${ }^{40}$ Although these studies are limited by being based on single candidate genes and single cognitive biases, they raise the possibility that biased cognitive processing may result from $\mathrm{G} \times \mathrm{E}$ interactions and mediate affective outcomes.

In terms of establishing a possible mechanism for this mediation, the ideal study would experimentally manipulate the environment to determine whether genetic variation influences the development of cognitive biases in different environmental contexts. Experimentally manipulating the environment would reduce the possibility of gene-environment correlation, which can undermine the ability to accurately interpret $G \times E$ interactions. ${ }^{41,42,43}$ Specifically, it would be particularly informative to determine whether manipulating the affective learning environment can result in enhanced negative and positive processing biases in the attention system in people who should be more genetically sensitive to the environment. This was achieved in a study utilizing an $A B M$ intervention designed to induce either a positive $A B$ or a negative $A B$ in different groups of participants. ${ }^{44}$ It was found that healthy adults with two copies of the 5-HTTLPR S-allele developed stronger ABs than those with two copies of the L-allele. This was observed whether the induction was designed to encourage a negative bias or a positive bias. The demonstration that those genetically sensitive to the environment develop negative or positive attention biases depending on the environmental context suggests that $A B$ may be an important phenotype that mediates the development of subsequent psychopathology or adaptive functioning.

Given the association between selective cognitive processing and emotional wellbeing ${ }^{8}$ along with the demonstration of differential susceptibility to a cognitive intervention ${ }^{44}$ we propose the following theoretical model: specific early environmental events (either negative or positive) combined with genetic variants that enhance sensitivity to the environment might contribute to the development of 'toxic' or 'enhancing' cognitive biases that, in turn, influence the impact of subsequent experiences on wellbeing (see Figure 1). This 'Cognitive Bias' (CogBIAS) hypothesis predicts that once a negative cognitive bias is in place, future information processing is skewed and reinforces sensitivity to negative environments resulting eventually-in combination with other factors - to affective disorders, such as anxiety or depression. Conversely, a supportive early environment could cultivate an enhancing cognitive bias (for example, selective attention for positive information or strategic avoidance of negative cues) that could help an individual to thrive. The CogBIAS model offers one possible mechanism that might be responsible for differential susceptibility.

If $\mathrm{G} \times \mathrm{E}$ interactions are indeed mediated by changes in cognitive processes (for example, negative or positive $A B$ ), then targeting these processes is likely to be critical for improving the

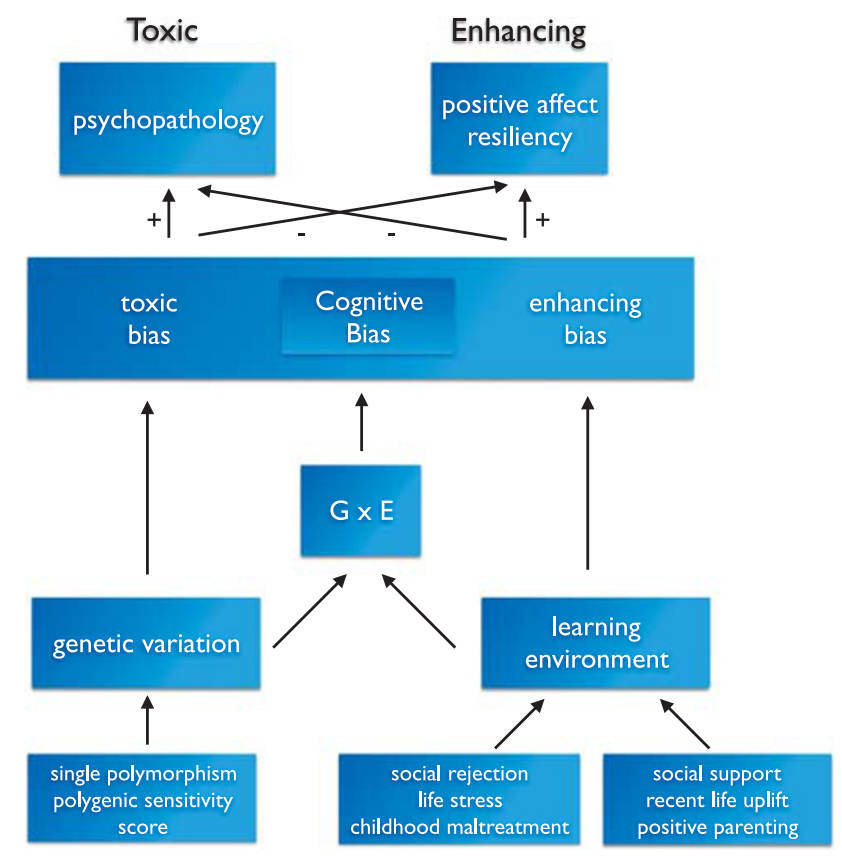

Figure 1. Illustration of the Cognitive Bias (CogBIAS) model detailing how specific cognitive biases may mediate differential susceptibility to the environment. $\mathrm{G} \times \mathrm{E}$, gene by environment.

efficacy of new behavioral interventions for anxiety and depression. ${ }^{44,45}$ Personalized interventions could be designed to encourage people who are genetically sensitive to the environment to develop a more flexible pattern of attentional orienting to avoid a persistent tendency to focus on negativity in adverse situations, but to selectively process positive material in highly supportive environments. In contrast, reduced affective reactivity observed in those less genetically sensitive to the environment should, of course, serve as a natural protective factor in adverse situations, whereas more intensive interventions might be required to ensure the development of cognitive processing styles that enhance wellbeing, perhaps by helping people maximize the benefits of positivity and supportive environments. This is highly speculative at the moment, of course, but future developments in translating basic science research in cognitive psychology has the potential to lead to real breakthroughs in the development of novel therapeutic interventions ${ }^{46}$ and the potential to move towards more personalized treatment strategies. ${ }^{47,48}$

\section{LIMITATIONS OF PREVIOUS RESEARCH AND THE WAY FORWARD}

Although both cognitive and genetic research has identified potential markers of psychopathology, samples sizes are typically small, studies usually investigate only a single bias (primarily $A B$ ) or single-genetic variant (for example, 5-HTTLPR), and environmental variation has typically not been considered. However, cognitive biases have been linked to genetic variation, environmental context, and $\mathrm{G} \times \mathrm{E}$, indicating that evaluating the combined impact of cognitive biases and genetic polymorphisms on the development of psychopathology and wellbeing is likely to be complex and challenging as well as informative.

A particularly serious challenge for psychiatric genetics is small effect sizes of individual genetic variants that typically explain only about $0.5 \%$ of the variance (at best) in psychopathology in GWAS. Summing so-called 'risk' alleles across different single nucleotide polymorphisms, however, has been used to produce a Polygenic 'Risk' Score (PRS) ${ }^{49}$ yielding a quantitative index with a potentially 
larger effect size than a single-genetic variant. The PRS approach has been used to model the cumulative contribution of genetic variation to cardiovascular disease, ${ }^{50,51}$ among other outcomes. We suggest that the term 'PSS' is more appropriate in light of the fact that enhanced reactivity and sensitivity to the environment operates in both adverse and supportive environments. To date, however, in psychiatry the polygenic approach has typically been used to predict variation in the negative end of the environmental spectrum (that is, PRSs).

To illustrate, PRSs have been successful in predicting increased risk of moving from light to heaving smoking in the teenage years, ${ }^{52}$ increased risk of clinical obesity, ${ }^{53}$ smoking relapse in response to pharmacologic treatment, ${ }^{54}$ adolescent self-regulation in adverse and supportive environments, ${ }^{55}$ and prediction of rumination in the context of life stress. ${ }^{56}$ There is also evidence that a small serotonergic PRS is associated with negatively biased attention following a negative mood induction, ${ }^{57}$ whereas a PRS developed from a GWAS study in major depression disorder has been shown to predict reduced cortical thickness in left medial frontal cortex; a region known to be disrupted in major depression disorder. ${ }^{58}$ A recent GWAS study has developed what we might call a PSS and found support for differential susceptibility in terms of heightened emotionality and response to psychological therapy in children with anxiety disorders. ${ }^{36}$

The PSS approach holds much promise for measuring genetic contributions to cognitive biases and other phenotypes relating to differential susceptibility. An important way forward will be for the field to develop much more comprehensive PSSs that likely include 1000 s of genetic variants with the potential to predict substantially more variance than PSSs with a limited number of variants.

Once comprehensive PSSs have been developed, they could then be used in conjunction with detailed and precise measurements of the environment. However, an important priority as we move forward is the development of innovative techniques to assess both positive and negative environments. Much of past research is limited by a reliance on retrospective recall, often via self-report. $^{59}$ Although interview techniques have significant strengths, they too rely on retrospective recall and can be very time intensive. Further, most prior research has focused on the negative aspects of the environment, which likely provides an incomplete understanding of the interplay between genetics, the environment and development of cognitive bias.

Measuring positive and negative experiences, as they happen, almost in real-time, via ecological momentary assessments is difficult to achieve on a large scale, but as smartphones become more pervasive, collection of data about the environment is becoming increasingly feasible. ${ }^{60}$ Indeed, as computing power increases, it may soon be possible to reliably collect cognitive bias assessments in real-world environments via smartphones. Because smartphones are unobtrusive and sensor-rich, they facilitate measurement of real-world behaviors and experiences as they happen. ${ }^{61}$ Measurement can include objective behavior, such as activity level via imbedded accelerometers or location via globalpositioning systems. Ecological momentary assessments can also significantly reduce or eliminate retrospective recall bias for more subjective assessments. Although ecological momentary assessment methods are not a panacea, these methods may greatly facilitate assessment of psychological experiences that closely reflect real-world experiences.

In our view, it is also critical to develop more reliable methods to assess cognitive processing biases. Although computational modeling to characterize cognitive biases has received little attention in psychiatry, several studies show that diffusion models reveal processing biases in clinically relevant populations that are not typically observed by traditional reaction time or accuracy assessments. ${ }^{62,63} \mathrm{~A}$ second important approach will be to develop brain-based phenotypes. ${ }^{64}$ Such assessments could include direct measurement of neural function associated with cognitive bias, or cognitive bias tasks that strongly correspond with known brain function. As suggested in other reviews, ${ }^{4}$ there is much uncertainty about the neural processes that mediate the effects of environment on developmental outcomes. We suggest that there is also uncertainty about the role of cognitive processing biases in mediating differential susceptibility. However, enhancing the assessment of cognitive bias will facilitate a better understanding of the precise cognitive mechanisms that give rise to emotional vulnerability or wellbeing among individuals genetically susceptible to environmental change.

More robust genetic methods, better measurements of cognitive bias and capturing environmental influence as it unfolds, is, however, only a starting point for understanding the mechanisms involved in the differential susceptibility model. Given that statistical interactions require substantially more statistical power than main effects, it has been argued that sample sizes may need to be in the tens of thousands to have adequate statistical power for $\mathrm{G} \times \mathrm{E}$ studies leading some to suggest that most $\mathrm{G} \times \mathrm{E}$ studies to date are likely false positives. ${ }^{65}$ Several excellent suggestions for how to examine genetic interactions without requiring samples of 50000 people or more have been suggested. ${ }^{43,66}$ One approach is to limit $\mathrm{G} \times \mathrm{E}$ tests to those variants or PRSs that show main effects for the phenotype of interest in GWAS studies. ${ }^{67}$ This approach is ideal for testing traditional diathesis-stress relationships; however, because differential susceptibility relies on crossover interactions ${ }^{43}$ limiting $\mathrm{G} \times \mathrm{E}$ tests to genetic variants with main effects will only potentially dismiss promising candidates. A major re-think of methodological approach may be required in order to accommodate differential susceptibility.

The most stringent test of the DSH is provided by randomizedcontrolled trials examining the moderating role of genetic variants when the environment is manipulated 'experimentally' (Genex Experimental Environment $(\mathrm{G} \times \mathrm{eE})$ interactions). ${ }^{42,43}$ Intervention studies utilizing both positive and negative environments, such as the ABM study mentioned earlier, ${ }^{44}$ have at least three distinct advantages over typical correlational and longitudinal studies, including most GWAS. ${ }^{43}$ First, $G$ and $E$ are uncorrelated in experimental designs providing the real advantage of independence between any change in the environment and genetic profile. Second, the degree of measurement error of the environment is vastly reduced in experimental studies. Third, and perhaps most significantly, because intervention studies stimulate the experimental group to differ maximally from the control group the statistical power of experimental $\mathrm{G} \times \mathrm{eE}$ studies is much larger than correlational studies. Indeed, one set of simulations indicated that a correlational $\mathrm{G} \times \mathrm{E}$ study requiring 1300 participants would require only 100 participants in an experimental $\mathrm{G} \times \mathrm{eE}$ study to achieve the same degree of statistical power. ${ }^{68}$

\section{CONCLUSION}

The time now seems ripe to assess $\mathrm{G} \times \mathrm{E}$ interactions in studies that incorporate both negative and positive environments, include assessments of cognitive biases, and include 'PSS' that provide a cumulative spectrum of genetic 'risk' or 'enhancement' rather than focusing on a single polymorphism within a gene. We have proposed the novel CogBIAS hypothesis predicting that the development of toxic or enhancing cognitive biases may be an important mediator of $\mathrm{G} \times \mathrm{E}$ and $\mathrm{G} \times \mathrm{eE}$ effects in both adverse and positive environments. The CogBIAS hypothesis proposes that environmental events shape the learning environment that work in concert with genetic variation to produce negative or positive cognitive biases that, in turn, have a powerful influence on the development of negative (anxiety, depression) or positive (happiness, thriving) outcomes. Additional research is needed to explicitly test the tenants of this model, particularly the interaction 
between genetic variation and positive learning environments. This will facilitate a better understanding of wellbeing, resilience and psychopathology and holds great promise for the development of new personalized therapies.

\section{CONFLICT OF INTEREST}

The authors declare no conflict of interest.

\section{ACKNOWLEDGMENTS}

This work was supported by the European Research Council (ERC) under the European Union's Seventh Framework Programme (FP7/2007-2013)/ERC grant agreement no. [324176] to EF, and by a National Institute on Drug Abuse (5R01DA032457) and Brain and Behavior Foundation Independent Investigator awards to CGB.

\section{REFERENCES}

1 Belsky J, Jonassaint C, Pluess M, Brummett B, Williams R. Vulnerability genes or plasticity genes? Mol Psychiatry 2009; 14: 746-754.

2 Belsky J, Pluess M. Beyond diasthesis stress: differential susceptibility to environmental influences. Psychol Bull 2009; 135: 895-908.

3 van ljzendoorn MH, Bakermans-Jranenburg MJ. Genetic differential susceptibility on trial: Meta-analytic support from randomized controlled experiments. Dev Psychopathol 2015; 27: 151-162.

4 Moore R, Depue RA. Neurobehavioral foundations of environmental reactivity. Psych Bull 2016; 142: 107-164.

5 Fox E, Cahill $\mathrm{S}$, Zougkou K. Preconscious processing biases predict emotional reactivity to stress. Biol Psychiatry 2010; 67: 371-377.

6 Wald I, Degnan KA, Gorodetsky E, Charney DS, Fox NA, Fruchter E et al. Attention to threats and combat-related posttraumatic stress symptoms: prospective associations and moderation by the serotonin transporter gene. JAMA Psychiatry 2013; 70: 401-408.

7 Bar-Haim Y, Lamy D, Pergamin L, Bakermans-Kranenburg M, van ljzendoorn M. Threat-related attentional bias in anxious and non-anxious individuals: a metaanalytic study. Psychol Bull 2007; 133: 1-24.

8 Mathews A, MacLeod C. Cognitive vulnerability to emotional disorders. Ann Rev Clin Psychol 2005; 1: 167-195.

9 Cisler JM, Koster EHW. Mechanisms of attentional biases towards threat in anxiety disorders: An integrative review. Clin Psychol Rev 2010; 30: 203-216.

10 MacLeod C, Rutherford E, Campbell L, Ebsworthy G, Holker L. Selective attention and emotional vulnerability: assessing the causal basis of their association through the experimental manipulation of attentional bias. J Abnormal Psychol 2002; 111: 107.

11 Heeren A, Reese HE, McNally RJ, Philippot P. Attention training toward and away from threat in social phobia: effects on subjective, behavioral, and physiological measures of anxiety. Behav Res Ther 2012; 50: 30-39.

12 Hakamata Y, Lissek S, Bar-Haim Y, Britton JC, Fox NA, Leibenluft E et al. Attention bias modification treatment: a meta-analysis toward the establishment of a novel treatment for anxiety. Biol Psychiatry 2010; 68: 982-990.

13 Hallion LS, Ruscio AM. A meta-analysis of the effect of cognitive bias modification on anxiety and depression. Psychol Bull 2011; 137: 940-958.

14 Cristea IA, Kok RN, Cuijpers P. Efficacy of cognitive bias modification interventions in anxiety and depression: a meta-analysis. Br J Psychiatry 2015; 206: 7-16.

15 Clarke PJF, Notebaert L, MacLeod C. Absence of evidence or evidence of absence: reflecting on therapeutic implementations of attentional bias modification. BMC Psychiatry 2014; 14: 8 .

16 Fox E, Mackintosh B, Holmes EA. Travellers' tales in cognitive bias modification research: a commentary on the special issue. Cog Ther Res 2014; 38: 239-247.

17 Dick DM, Agrawal A, Keller MC, Adkins A, Aliev F, Monroe S et al. Candidate geneenvironment interaction research: reflections and recommendations. Persp Psychol Sci 2015; 10: 37-59.

18 Kendler KS, Kessler RC, Walters EE, MacLean C, Neale MC, Heath AC et al. Stressful life events, genetic liability, and onset of an episode of major depression in women. Am J Psychiatry 1995; 152: 833-842.

19 Caspi A, Sugden K, Moffitt TE, Taylor A, Craig IW, Harrington H et al. Influence of life stress on depression: moderation by a polymorphism in the $5-\mathrm{HTT}$ gene. Science 2003; 301: 386-389.

20 Zalsman G, Huang Y-Y, Oquendo MA, Burke AK, Hu X-Z, Brent DA et al. Association of a triallelic serotonin transporter gene promoter region (5-HTTLPR) polymorphism with stressful life events and severity of depression. Am J Psychiatry 2006; 163: 1588-1593
21 Caspi A, Hariri AR, Holmes A, Uher R, Moffitt TE. Genetic sensitivity to the environment: the case of the serotonin transporter gene and its implications for studying complex diseases and traits. Am J Psychiatry 2010; 167: 509-527.

22 Barr CS, Newman TK, Becker ML, Parker CC, Champoux M, Lesch KP et al. The utility of the non-human primate; model for studying gene by environment interactions in behavioral research. Genes Brain Behav 2003; 2: 336-340.

23 Risch N, Herrell R, Lehner T, Liang KY, Eaves I, Hoh J et al. Interaction between the serotonin transporter gene (5-HTTLPR), stressful life events, and risk of depression: a meta-analysis. JAMA 2009; 301: 2462-2471.

24 Karg K, Burmeister M, Shedden K, Sen S. The serotonin transporter promoter variant (5-HTTLPR), stress, and depression meta-analysis revisited: evidence of genetic moderation. Arch Gen Psychiatry 2011; 68: 444-454.

25 Duncan LE, Keller MC. A critical review of the first 10 years of candidate gene-byenvironment interaction research in psychiatry. Am J Psychiatry 2011; 168: 1041-1049.

26 Belsky J, Bakermans-Kranenburg MJ, Van ljzendoorn MH. For better and for worse: Differential susceptibility to environmental influences. Curr Dir Psychol Sci 2007; 16: 300-304.

27 Ellis BJ, Boyce WT. Differential susceptibility to the environment: toward an understanding of sensitivity to developmental experiences and context. Dev Psychopathol 2011; 23: 1-5.

28 Taylor SE, Way BM, Welch WT, Hilmert CJ, Lehman BJ, Eisenberger NI. Early family environment, current adversity, the serotonin transporter promotor polymorphism, and depressive symptomatology. Biol Psychiatry 2006; 60: 671-676.

29 Eley TC, Sugden K, Corsico A, Gregory AM, Sham P, McGuffin P et al. Geneenvironment interaction analysis of serotonin system markers with adolescent depression. Mol Psychiatry 2004; 9: 908-915.

30 Hankin BL, Nederhof E, Oppenheimer CW, Jenness J, Young JF, Abela JRZ et al. Differential susceptibility in youth: evidence that 5 -HTTLPR $x$ positive parenting is associated with positive affect 'for better and worse'. Transl Psychiatry 2011; 1: e44.

31 Pluess M, Belsky J, Way BM, Taylor SE. 5-HTTLPR moderates effects of current life events on neuroticism: differential susceptibility to environmental influences. Prog Neuropsychopharmacol Biol Psychiatry 2010; 34: 1070-1074.

32 Kuepper Y, Wielpuetz C, Alexander N, Mueller E, Grant P, Hennig J. 5-HTTLPR S-allele: a genetic plasticity factor regarding the effects of life events on personality? Genes Brain Behav 2012; 11: 643-650.

33 Haase CM, Saslow LR, Bloch L, Saturn SR, Casey JJ, Seider BH et al. The 5-HTTLPR polymorphism in the serotonin transporter gene moderates the association between emotional behaviour and changes in marital satisfaction over time. Emotion 2013; 13: 1068-1079.

34 Mitchell C, Notterman D, Brooks-Gunn J, Hobcraft J, Garfinkel I, Jaeger K et al. Role of mother's genes and environment in postpartum depression. Proc Nat Acad Sci USA 2011; 108: 8189-8193.

35 Van ljzendoorn MH, Belsky J, Bakermans-Kranenburg MJ. Serotonin transporter genotype 5-HTTLPR as a marker of differential susceptibility? A meta-analysis of child and adolescent gene-by-environment studies. Transl Psychiatry 2012; 2: e147.

36 Keers R, Coleman JRI, Lester KJ, Roberts S, Breen G, Thatsum M et al. A genomewide test of the differential susceptibility hypothesis reveals a genetic predictor of differential response to psychological treatments for child anxiety disorders. Psychother Psychosom 2016; 85: 146-158.

37 Pergamin-Hight L, Bakermans-Kranenburg MJ, Van ljzendoorn MH, Bar-Haim Y. Variations in the promoter region of the serotonin transporter gene and biased attention for emotional information: a meta-analysis. Biol Psychiatry 2012; 71: 373-379.

38 Gibb BE, Mcgeary JE, Beevers CG. Attentional biases to emotional stimuli: key components of the RDoC constructs of sustained threat and loss. Am J Med Genet Neuropsychiatric Genet 2016; 171B: 65-80.

39 Osinsky R, Hennig J, Losch A, Alexander N, MacLeod C. Attentional bias to negative information and 5-HTTLPR genotype interactively predict students' emotional reactivity to first university semester. Emotion 2012; 12: 460-469.

40 Miu AC, Vulturar R, Chis A, Ungureanu L, Gross JJ. Reappraisal as a mediator in the link between 5-HTTLPR and social anxiety symptoms. Emotion 2013; 13: 1012-1022.

41 Moffitt TE, Caspi A, Rutter M. Strategy for investigating interactions between measured genes and measured environments. Arch Gen Psychiatry 2005; 62: 473-481.

42 van ljzendoorn $\mathrm{MH}$, Bakermans-Kranenburg MJ, Belsky J, Beach S, Brody G, Dodge KA et al. Gene-by-environment experiments: a new approach to finding the missing heritability. Nat Rev Genet 2011; 12: 881-881.

43 Bakermans-Kranenburg MJ, van Ijzendoorn MH. The hidden efficacy of interventions: Gene X environment experiments from a differential susceptibility perspective. Ann Rev Psychol 2015; 66: 381-409.

44 Fox E, Zougkou K, Ridgewell A, Garner K. The serotonin transporter gene alters sensitivity to attention bias modification: evidence for a plasticity gene. Biol Psychiatry 2011; 70: 1049-1054. 
45 Britton JC, Rauch SL. Attention bias modification and the serotonin transporter: personalized treatment implications of gene interactions with learning. Biol Psychiatry 2011; 70: 1004-1005.

46 Eley TC, Hudson JL, Creswell C, Tropeano M, Lester KJ, Cooper P et al. Therapygenetics: the 5-HTTLPT and response to psychological therapy. Mol Psychiatry 2012; 17: 236-241.

47 Lester KJ, Eley TC. Therapygenetics: using genetic markers to predict response to psychological treatment for mood and anxiety disorders. Biol Mood Anxiety Disord 2013; 3: 4.

48 Beevers CG, McGeary JE. Therapygenetics: moving towards personalized psychotherapy treatment. Trends Cogn Sci 2012; 16: 11-12.

49 International Schizophrenia Consortium, Purcell SM, Wray NR, Stone JL, Visscher PM, O'Donovan MC et al. Common polygenic variation contributes to risk of schizophrenia and bipolar disorder. Nature 2009; 460: 748-752.

50 Jones HJ, Stergiakouli E, Tansey KE, Hubbard L, Heron J, Cannon M et al. Phenotypic manifestation of genetic risk for schizophrenia during adolescence in the general population. JAMA Psychiatry 2016; 73: 221-228.

51 Kathiresan S, Melander O, Anevski D, Guiducci C, Burtt NP, Roos C et al. Polymorphisms associated with cholesterol and risk of cardiovascular events. $N$ Engl J Med 2008; 358: 1240-1249.

52 Belsky DW, Moffitt TE, Baker TB, Biddle AK, Evans JP, Harrington $\mathrm{H}$ et al. Polygenic risk and the developmental progression to heavy, persistent smoking and nicotine dependence. JAMA Psychiatry 2013; 70: 534-542.

53 Belsky DW, Moffitt TE, Houts R, Bennett GG, Biddle AK, Blumenthal JA et al. Polygenic risk, rapid childhood growth and the development of obesity. Arch Pediatr Adolesc Med 2012; 166: 515-521.

54 McGeary JE, Knopik VS, Hayes JE, Palmer RH, Monti PM, Kalman D. Predictors of relapse in a bupropion trial for smoking cessation in recently-abstinent alcoholics: preliminary results using an aggregate genetic risk score. Substance Abuse Res Treat 2012; 6: 107-114.

55 Belsky J, Beaver KM. Cumulative-genetic plasticity, parenting and adolescent self-regulation. J Child Psych Psychiatry 2010; 52: 619-626.

56 Clasen PC, Wells TT, Knopik VS, McGeary JE, Beevers CG. 5-HTTLPR and BDNF Val66Met polymorphisms moderate effects of stress on rumination. Genes Brain Behav 2011; 10: 740-746.

57 Disner SG, McGeary JE, Wells TT, Ellis AJ, Beevers CG. 5-HTTLPR, HTR1A, and HTR2A cumulative genetic score interacts with mood reactivity to predict mood-congruent gaze bias. Cogn Affect Behav Neurosci 2014; 14: 1259-1270.

58 Holmes AJ, Lee PH, Hollinshead MO, Bakst L, Roffman JL, Smoller JW et al. Individual differences in amygdala-medial prefrontal anatomy link negative affect, impaired social functioning, and polygenic depression risk. J Neurosci 2012; 32: 18087-18100.

59 Monroe SM, Reid MW. Gene-environment interactions in depression research: genetic polymorphisms and life-stress polyprocedures. Psych Sci 2008; 19: 947-956.

60 Miller G. The smartphone psychology manifesto. Pers Psych Sci 2012; 7: 221-237.

61 Burns MN, Begale M, Duffecy J, Gergle D, Karr CJ, Giangrande E et al. Harnessing context sensing to develop a mobile intervention for depression. J Med Internet Res 2011; 13: e55.

62 White CN, Ratcliff R, Vasey MW, McKoon G. Anxiety enhances threat processing without competition among multiple inputs: a diffusion model analysis. Emotion 2010; 10: 662-677.

63 Pe ML, Vandekerckhove J, Kuppens P. A diffusion model account of the relationship between the emotional flanker task and rumination and depression. Emotion 2013; 13: 739-747.

64 Green AE, Ograve MRM, DeYoung CG, Fossella JA, Fan J, Gray JR. Using genetic data in cognitive neuroscience: from growing pains to genuine insights. Nat $\mathrm{Rev}$ Neurosci 2008; 9: 710-720.

65 Duncan LE, Keller MC. A critical review of the first 10 years of candidate gene-byenvironment interaction research in psychiatry. Am J Psychiatry 2011; 168: 1041-1049.

66 Vrieze SI, lacono WG, McGue M. Confluence of genes, environment, development, and behavior in a post Genome-Wide Association Study world. Dev Psychopathol 2012; 24: 1195-1214

67 Roisman GI, Newman DA, Fraley RC, Haltigan JD, Groh AM, Haydon KC. Distinguishing differential susceptibility from diathesis-stress: recommendations for evaluating interaction effects. Dev Psychopathol 2012; 24: 389-409.

$68 \mathrm{McClelland}$ GH, Judd CM. Statistical difficulties of detecting interactions and moderator effects. Psychol Bull 1993; 114: 376-390.

(c) $($ ) This work is licensed under a Creative Commons Attributioncc. ${ }_{\mathrm{BY}} \mathrm{NC}_{\mathrm{ND}}$ NonCommercial-NoDerivs 4.0 International License. The images or other third party material in this article are included in the article's Creative Commons license, unless indicated otherwise in the credit line; if the material is not included under the Creative Commons license, users will need to obtain permission from the license holder to reproduce the material. To view a copy of this license, visit http:// creativecommons.org/licenses/by-nc-nd/4.0/

(c) The Author(s) 2016 